Opinion

\title{
Rise of Insolation of Low Latitudes Affects Arctic Warming
}

\author{
Genrikh Alekseev* \\ Arctic and Antarctic Research Institute, St Petersburg, Russia
}

Keywords: Warming,Earth, Climate, Air,Temperature, Water

\section{Opinion}

Global numerical models of the Earth's climate system are the main tool for obtaining quantitative estimates of changes in the Earth's climate caused by anthropogenic activities. New findings from these models are regularly discussed and summarized in the Assessment reports of the Intergovernmental Panel on Climate Change (IPCC). The Sixth report is currently being prepared for release and is expected to becompleted this year. The release is preceded by an analysis of numerical experiments performed in accordance with the agreed list of global models for the CMIP6 ensemble. The previous ensemble of CMIP5 calculations was used in the preparation of the IPCC report issued in 2014. Since then, the models have been improved and refined taking into account the recommendations based on the analysis of CMIP5 calculations.

The first calculations for the new ensemble showed a higher equilibrium sensitivity to a doubling of $\mathrm{CO}_{2}$ concentration relative to pre-industrial levels compared to CMIP5 models $\left(5^{\circ} \mathrm{C}\right.$ instead of $\left.4.5^{\circ} \mathrm{C}\right),{ }^{1}$ which has not yet been explained. However, past climate changes recorded in ice cores do not confirm the high climate sensitivity, as well as the rate of current warming. On February 2020, ${ }^{2}$ the WCRP High-level Science Questions and Flagship Workshop was held in Hamburg, Germany, which discussed scientific issues for the next decade and knowledge gaps that should be taken into account when preparing the IPCC reports. Among the challenges highlightedfor the next decade were the climate sensitivity to greenhouse gas emissions and the effects of warming in excess of the Paris Agreement levels (Guy Brasseur). It was pointed out an unacceptable bias of the model estimates, whichdoes not allow moving on (MojibLatif). As noted in the discussion, in some areas the same issues remain as they were 20years ago. For example, the problem of climate sensitivity has not been solved in 40years. JochemMarotzke indicated that many of the knowledge gaps sections in the forthcoming IPCC assessment are still under development. Bjorn Stevens noted that models are a tool that can be used in conjunction with other tools and that various assessment methods should be used.

The analysis of model calculations from the CMIP5 ensemble ${ }^{3}$ showed that the models underestimate the magnitude of the observed interdecadal variability and distort its spatial character. Noteworthy is the underestimation in the models of the positive trends in ocean warming at low latitudes, where most of the heat of solar radiation is accumulated..$^{4-7}$ As a result, global coupled models are less likely to reproduce climate change features in selected regions in mid and high latitudes than atmospheric circulation models with observed warming in tropical oceans. ${ }^{8-10}$ Meanwhile, the influence of tropical oceans on climate change in mid and high latitudes was noted in. ${ }^{11,12}$

As it is shown $\mathrm{in}^{13}$ the global coupled models from CMIP5 largely underestimate the interannual temperature variability in the Atlantic water layer in the Arctic Ocean, and underestimate its trend observed since the late 1970s. In the new generation of global models from CMIP6, the largest discrepancy between the observed and modeled distribution of sea ice in the Arctic is still observed

\begin{tabular}{|l|l|}
\hline Quick Response Code: & *Corresponding author: Genrikh Alekseev, Arctic and Antarctic Research Institute, St Peters- \\
burg, Russia \\
Received: 07 April, $2021 \quad$ Published: 26 April, 2021 \\
Citation: Genrikh Alekseev. Rise of Insolation of Low Latitudes Affects Arctic Warming.Glob \\
Scient Res Env Sci. 2021;1(3):1-3. D0I: 10.53902/GSRES.2021.01.000514
\end{tabular}


in September and has been increasing since the beginning of the twenty-first century. Most of the models from CMIP6 show less September ice loss per degree of warming compared to observations. ${ }^{14}$

From the viewpoint of authors of the peer-reviewed papers, the reasons for the discrepancy between simulated and observed warming in the tropical oceans is that the radiative forcing on warming in recent decades has been rather small or some important processes in the tropics have not been taken into account in coupled models, ${ }^{8}$ or models underestimate internal variability. ${ }^{6}$

In our studies of the influence of the tropics on climate change in the Arctic, one more, in our opinion, the main reason for the discrepancies was found, namely, the absence in global models of a positive insolation trend in the radiative forcing at the top of the

Table 1: Trends of average insolation for the region 0-25 $\mathrm{N}\left(\mathrm{Wm}^{-2} \mathrm{yr}^{-1} \times 100\right)$ for 1979-2018 calculated on data obtained from /http://www.solar-climate. $\mathrm{com} /$. Positive trends are highlighted in bold.

\begin{tabular}{|c|c|c|c|c|c|c|}
\hline Month & January & February & March & April & May & July \\
\hline Trend & 0.056 & 0.23 & 0.344 & 0.422 & 0.398 & 0.26 \\
\hline Month & August & September & October & November & December & $\sum_{1}{ }^{2} t_{m}$ \\
\hline Trend & -0.19 & -0.359 & -0.388 & -0.282 & -0.109 & $\sum_{1}{ }^{12}{ } r_{m}$ \\
\hline
\end{tabular}

Thus, global warming develops with the participation of an increase in insolation of TOA at low latitudes and intensifies in the Arctic under the influence of atmospheric and oceanic transport of heat and moisture.Global climate models simulate ocean warming at low-latitudes insufficiently correct due to underestimation of rise in insolation of the top of the atmosphere and, thereby do not take into consideration one of thefactors of climate warming.

\section{Acknowledgments}

Results of Russian Fund of Basic Research (RFBR) grants 1805-00334 and 18-05-60107 are used.The author thanks Dr. S. Soldatenko for help in preparing the manuscript.

\section{Funding}

None.

\section{Conflicts of Interest}

Author declares that there is no conflict of interest.

\section{References}

1. Voosen Paul. New climate models predict a warming surge. Science. 2019;364(6437):222-223.

2. World Climate Research Programme. WCRP High-level Science Questions and Flagship Workshop, Hamburg, Germany. 2020.

3. Kravtsov S. Pronounced differences between observed and CMIP5simulated multidecadal climate variability in the twentieth century, Geophys. Res Lett. 2017;44:5749-5757.

4. Palmer MD, Good SA, Haines K, et al. A new perspective on warming of the global oceans, Geophys. Res Lett. 2009;36:L20709.

5. IPCC. Climate Change 2013: The Physical Science Basis. Contribution of Working Group I to the Fifth Assessment Report of the Intergovernmental Panel on Climate Change. Stocker TF, Qin D, Plattner GK, et al, editors. Cambridge University Press, Cambridge, United Kingdom and New York, NY, USA. 2013;1535.
atmosphere(TOA) at low latitudes. The largest amount of solar radiation arrives at low latitudes of the Earth, wherean increase in insolationat the TOAis observed. ${ }^{15-18}$

Although these changes in insolation as a result of the Earth's orbital dynamics are small (Table1), their influence is enhanced by the accumulation of heat in the ocean, which makes up most of the area of low latitudes, low ocean albedo and nonlinear feedbacks between temperature, water vapor content and downward long-wave radiation. As a result, a slight long-term increase in insolation in spring and early summeris accompanied by a noticeableincrease in sea surface temperature, air temperature, water vapor content anddownward long-wave radiation in autumn, which ultimately affects warming in the Arctic in winter in 2-3years. ${ }^{19-21}$

6. Laepple T, Huybers. Global and regional variability in marine surface temperatures, Geophys. Res Lett. 2014;41.

7. Bilbao Roberto AF, Jonathan M Gregory, NathaelleBouttes, et al. Attribution of ocean temperature change to anthropogenic and natural forcings using the temporal, vertical and geographical structure. Clim Dyn. 2019;53:5389-5413.

8. Barsugli JJ, Shin SI, Sardeshmukh PD. Sensitivity of global warming to the pattern of tropical ocean warming. Clim Dyn. 2006;27:483-492.

9. Shin SI, Sardeshmukh. Critical influence of the pattern of tropical ocean warming on remote climate trends. Climate Dyn. 2011;36:1577-1591.

10. Ding Qinghua, John M Wallace, David S Battisti, et al. Tropical forcing of the recent rapid Arctic warming in northeastern Canada and Greenland. Nature. 2014;509:209-212.

11. Hoerling MP, Hurrell JW, Xu T. Tropical origins for recent North Atlantic climate change. Science. 2001;292:90-92.

12. Meehl GA, Chung CTY, Arblaster JM, et al. Tropical decadal variability and the rate of Arctic sea ice decrease. Geophysical Research Letters. 2018;45(11):326-333.

13. Shu Qi, Qiang Wang, Jie Su, et al. Assessment of the Atlantic water layer in the Arctic Ocean in CMIP5 climate models. Climate Dynamics. 2019;53:5279-5291.

14. Mengyuan Long, Lujun Zhang, Siyu Hu, et al. Multi-Aspect Assessment of CMIP6 Models for Arctic Sea Ice Simulation. JC. 2021;34(4):1515-1529.

15. Borisenkov EP, Tsvetkov AV, Eddy JA. Combined effects of Earth orbit perturbations and solar activity on terrestrial insolation. Part 1: Sample days and annual mean values. J Atmos Sci. 1985;42(9):933.

16. Borisenkov EP, Tsvetkov AV, Agaponov SV. On Some Characteristics of Insolation Changes in the Past and the Future. Clim Chang. 1983;5:237244.

17. Fedorov VM. Insolation of the Earth and modern climate changes. M: Fizmatlit. 2018;232.

18. http://www.solar-climate.com/

19. Alekseev GV, Glok NI, Vyazilova AE, et al. Climate change in the Arctic: causes and mechanisms. IOP Conference Series, EES 606, EESE6061(002). 2020. 
20. Alekseev GV, Kuzmina S, Bobylev L, et al. Impact of atmospheric heat and moisture transport on the Arctic warming. Int J Climatol. 2019;1-11.

21. Alekseev GV, Vyazilova AE, Glock NI, et al. Influence of water temperature anomalies in low latitudes of the ocean on the fluctuations in the
Arctic climate and their predictability. Arctic: Ecology and Economics. 2019;3(35):73-83. 